\title{
Prognostic Factors of Short-Term Outcome of Low Back Pain in Patients Attending Health Insurance Clinics in Sharkia Governorate, Egypt
}

\author{
Khaled Kasim, ${ }^{1,2}$ Abedel-Aziz El Sadak, ${ }^{1}$ Haytham Hassan, ${ }^{1}$ \\ Alaa Abdel-Wahed, ${ }^{1}$ and Samy Shaaban ${ }^{1}$ \\ ${ }^{1}$ Department of Public Health and Community Medicine, Al-Azhar Faculty of Medicine, Nasr city, Cairo, Egypt \\ ${ }^{2}$ Department of Family and Community Medicine, Faculty of Medicine, Taibah University, Madinah, Saudi Arabia \\ Correspondence should be addressed to Khaled Kasim, kasimyhr@yahoo.com
}

Received 21 August 2011; Accepted 13 September 2011

Academic Editors: B. Netterstrøm and K. M. Rospenda

Copyright (๑) 2012 Khaled Kasim et al. This is an open access article distributed under the Creative Commons Attribution License, which permits unrestricted use, distribution, and reproduction in any medium, provided the original work is properly cited.

Objectives. This study aimed to determine the predictors of short-term outcome of low back pain (LBP) in a cohort of LBP patients. Subjects and Methods. A prospective cohort of 400 LBP patients who attending the health insurance clinics at Al-Hussinia city, Sharakia governorate, Egypt, were the subjects of this study. The data were collected by using a predesigned questionnaire at the index consultation. The outcome variable (good versus bad outcome), in terms of return to work, was collected one/two weeks later on the next consultation or by telephone. Statistical analyses including predictive regression analysis was done. Results. Out of the analysed 349 patients, there have been 202 patients (58\%) with good back pain outcome. Logistic regression analyses showed that the factors most significantly associated with good back pain outcome were the recency of pain $(\mathrm{OR}=4.85 ; 95 \% \mathrm{CI}=2.88-8.17)$, patient's occupation $(\mathrm{OR}=2.11 ; 95 \% \mathrm{CI}=1.33-3.35)$ and absence of obesity $(\mathrm{OR}=2.70 ; 95 \% \mathrm{CI}=1.15-5.22)$. Other significant less important factors were age of the patient, and site of pain. Conclusions. Reliable information on back pain related history, patient's occupation, body mass index and age of the patient at the index consultation are important to assess short-term prognosis in LBP patients.

\section{Introduction}

Low back pain (LBP) is a common public health problem, especially in Western Europe and North America. In these countries, low back pain is one of the most common reasons for consulting a primary care physician [1]. Most of LBP patients, particularly those in their first episodes, recover within a short period of time and return back to their regular work [2]. Prediction of factors associated with good outcome LBP patients would help physician to pick up those with suspected poor LBP outcome to offer them more intensive treatment before the chronicity sets in [3].

Although several recent and previous studies have analysed LBP patients in several settings, including the primary care clinics, to determine the prognostic factors that predict the long-term outcome of LBP [4-7], the present knowledge on the short-term course of LBP patients, particularly among workers, seems to be rather poor and still under research, particularly in our region. Two-thirds of the articles about this health problem were contributed from authors within North America with a greater emphasis on prevention [8]. Furthermore, it has recently been reported that the return to work after an episode of LBP is influenced not only by clinical but also by social, lifestyle, economic, and other work-related factors [9]. From this point of view, it is clearly needed to investigate the outcome of LBP patients while taking into consideration the influence of the above-mentioned factors. The goal of this prospective cohort study is to improve the understanding of the determinants of the shortterm outcome of low back pain in our region. The specific objective of this study is to determine the most important sociodemographic, lifestyle, and pain-related factors that predict the good back pain outcome, in terms of return to work, among worker patients attending the health insurance clinics in Sharkia governorate, Egypt. 


\section{Subjects and Methods}

The setting for this study was the health insurance clinics at Al-Hussinia city, Sharkia governorate, Egypt. Worker patients attending these clinics were eligible for this study if they have had a nonspecific back pain. Thus, the resulting study cohort was the worker patients with nonspecific back pain seen by the health insurance care physicians. The study cohort included 400 eligible patients. One/two weeks after the index visit, subjects were invited to come back for reconsultation to determine the outcome of LBP. All studied patients were given nonsteroidal anti-inflammatory drugs and sick leaves for 5 days. Telephone interview were carried out for those patients not attending the clinic two weeks after index consultation. At the end of two weeks, the outcome of LBP was recorded for only 349 patients.

The data were collected by using a predesigned questionnaire at the index consultation, while the outcome variable (good versus poor outcome) was collected two weeks later on the next consultation or by telephone. The data on the outcome variable were collected from only 349 of the studied patients representing $87 \%$ of the total studied subjects. The study outcome was defined in two categories (good outcome $=1$ versus poor outcome $=2)$. The good outcome category is defined as the return to regular work in a good health. The poor outcome category has included those patients with fair and bad outcomes, where the patients did not return to their regular work and need more therapy and sick leaves. The collected independent (prognostic variables were classified into the following three categories: (i) sociodemographic factors: age, sex, education, and occupation; (ii) lifestyle risk factors: smoking, physical activity, and body mass index; (iii) history concerning back pain including grade, site, and type of pain.

Statistical analyses were performed by using the Statistical Analysis Software system (SAS) [10]. The subject characteristics were compared by the two outcome groups (good and poor) using the chi-square test for the studied variables treated in categories and $t$-test for the studied continuous variables. The $P$ value less than 0.05 is considered to be significant in these preliminary descriptive analyses. The prognostic value of the studied variables for the good back pain outcome was assessed using logistic regression. The analyses were first performed, variable by variable (univariate analyses). Then, all the variables with a statistically significant association with the outcome variable (good back pain outcome) were included in the final predictive model based on the stepwise regression analysis with the inclusion and exclusion criteria being SLE $=0.10$ and SLS $=0.15$.

\section{Results}

Of the studied 400 worker patients included in the index consultation database, the data on the outcome variable were collected from only 349 patients representing $87 \%$ of the total studied subjects. This dropout, however, did not differ from the rest of the cohort by the sociodemographic characteristics, lifestyle, and the type of back pain. Of these 349 studied subjects, there were $202(58 \%)$ with good back pain outcome and $147(42 \%)$ with poor outcome at the end of 2-week period. The mean age in the good outcome group was $37.4 \pm 10.5$, while it was $39.8 \pm 10.7$ in the other poor outcome group with a significant statistical difference between the two groups ( $P=0.003)$. The baseline characteristics of the two outcome group patients in relation to the studied variables are shown in Table 1; the two groups appeared to be similar with respect to lifestyle and most of the sociodemographic factors with the exception of age, education, and occupation. There has been statistically significant difference between the two outcome groups only in the pain-episode-related factors with $P$ value $<0.001$.

Table 2 shows the result of the logistic regression univariate analysis. There has been a significant positive association between the good back pain outcome and the following variables: age (less than 50 years), high education (more than secondary school), never smoking (nonsmokers), occupation (professional work), and all variables concerning the history of back pain episode (mild, localised, and recent pain). The highly significant positive association was in pain-related factors in terms of recent type of pain $(\mathrm{OR}=5.39 ; 95 \% \mathrm{CI}=3.38-8.57)$. Adjusting for the confounding effects in multivariate models did not change the estimated odds ratios and the observed significant association between these factors and the study outcome. From this point of view, the study has only presented the unadjusted odds ratios, estimated by the univariate analyses to facilitate their interpretation.

Table 3 presented the results of the predictive regression model. All variables with statistically significant odds ratios were included in this predictive model. The powerful predictors of good LBP outcome in this study were the recency of pain $(\mathrm{OR}=4.85 ; 95 \% \mathrm{CI}=2.88-8.17)$, normal weight subjects $(\mathrm{OR}=2.70 ; 95 \% \mathrm{CI}=1.15-4.22)$, the professional work $(\mathrm{OR}=2.16 ; 95 \% \mathrm{CI}=1.30-3.28)$, and patient's age less than 30 years $(\mathrm{OR}=1.90 ; 95 \% \mathrm{CI}=1.16-3.02)$ where there have been significant positive associations between these factors and the good LBP outcome.

\section{Discussion}

Although the literature is filled with information about the economic and individual impact of low back pain, the knowledge on factors affecting the prognosis of LBP in terms of return to work is still limited in Middle East countries, including Egypt. This short-term follow-up study has recruited LBP worker patients who consulted the health insurance care clinics at Al-Hussinia city, Sharkia governorate, Egypt, to investigate the prognostic factors that predict their short-term outcome. The outcome of LBP in terms of return to work was good for $58 \%$ of the studied worker patients attending the studied clinics, whereas the outcome was poor for the remaining $42 \%$.

The result of this study has shown that the good back pain outcome is influenced mainly by pain-related variables, occupation, body mass index, and age of the patient. The recency of back pain was the strongest predictor $(\mathrm{OR}=4.85 ; 95 \% \mathrm{CI}=2.88-8.17)$ in this study to influence the good back pain outcome compared with other significant 
TABLE 1: Baseline characteristics of the studied 349 patients according to their LBP outcome.

\begin{tabular}{|c|c|c|c|}
\hline Baseline characteristics & $\begin{array}{c}\text { Good BP outcome (202 subjects) } \\
\text { no. }(\%)^{*}\end{array}$ & $\begin{array}{c}\text { Poor BP outcome (147 subjects) } \\
\text { no. }(\%)^{*}\end{array}$ & $P$ value \\
\hline \multicolumn{4}{|c|}{ (i) Sociodemographic factors } \\
\hline Age in years $($ mean $\pm S D)$ & $37.4 \pm 10.5$ & $39.8 \pm 10.7$ & 0.003 \\
\hline Age group in years & & & 0.03 \\
\hline$<30$ & $52(26)$ & $31(21)$ & \\
\hline $30-50$ & $122(60)$ & $84(58)$ & \\
\hline$\geq 50$ & $28(14)$ & $32(21)$ & \\
\hline Sex & & & 0.27 \\
\hline Male & $119(59)$ & $80(55)$ & \\
\hline Female & $83(41)$ & $67(45)$ & \\
\hline Education & & & 0.002 \\
\hline Secondary and higher & $109(54)$ & $62(42)$ & \\
\hline Less than secondary & $93(46)$ & $85(58)$ & \\
\hline Occupation & & & 0.004 \\
\hline Professional & $34(17)$ & $38(26)$ & \\
\hline Skilled & $69(34)$ & $52(35)$ & \\
\hline Nonskilled & $99(49)$ & $57(49)$ & \\
\hline Body mass index $\left(\mathrm{kg} / \mathrm{m}^{2}\right)$ & & & 0.71 \\
\hline$<25$ & $101(50)$ & $75(51)$ & \\
\hline $25-<30$ & $81(40)$ & $43(29)$ & \\
\hline$\geq 30$ & $20(10)$ & $29(20)$ & \\
\hline \multicolumn{4}{|c|}{ (ii) Lifestyle factors } \\
\hline Smoking & & & 0.08 \\
\hline Never smoker & $69(34)$ & $61(42)$ & \\
\hline Ex-smoker & $61(30)$ & $41(28)$ & \\
\hline Smoker & $72(36)$ & $45(30)$ & \\
\hline Physical activity & & & 0.66 \\
\hline Yes & $123(61)$ & $87(59)$ & \\
\hline No & $79(39)$ & $60(41)$ & \\
\hline \multicolumn{4}{|c|}{ (iii) History of the index back pain episode } \\
\hline Pain grade & & & $<0.001$ \\
\hline Mild & $45(22)$ & $15(10)$ & \\
\hline Moderate & $125(62)$ & $79(54)$ & \\
\hline Severe & $32(16)$ & $53(36)$ & \\
\hline Pain site & & & $<0.001$ \\
\hline Localized & $106(52)$ & $50(34)$ & \\
\hline Radiated & $96(48)$ & $97(66)$ & \\
\hline Pain Type & & & $<0.001$ \\
\hline Recent & $60(30)$ & $18(12)$ & \\
\hline Periodic & $102(50)$ & $63(43)$ & \\
\hline Persistent & $40(20)$ & $66(45)$ & \\
\hline
\end{tabular}

prognostic factors. In contrast to this finding, Von Korff et al. [11] have not reported the recency of pain as an important predictor of back pain outcome. Although not included in the final predictive model, the severity of pain reported by subjects at time of index consultation is found to be a strong predictor of LBP outcome. This finding has appeared consistent with the results of Von Korff et al. [11] who reported the pain-related disability to be strong predictor of LBP outcome and others $[4,12]$ who found the baseline back pain intensity to be associated with short-term outcome of LBP. Regarding the other significant predictors in this study with respect to occupation, body mass index, age of the patient, and localized pain, the literature has also showed similar findings $[13,14]$. 
TABLE 2: Odds ratio and their $95 \%$ confidence intervals of good back pain outcome with the studied factors.

\begin{tabular}{|c|c|c|c|c|}
\hline Study variables & Good outcome (202 subjects) & Poor outcome (147 subjects) & $\mathrm{OR}^{*}$ & $95 \% \mathrm{CI}^{* *}$ \\
\hline \multicolumn{5}{|c|}{ (i) Sociodemographic factors } \\
\hline \multicolumn{5}{|l|}{ Age group in years } \\
\hline$<30$ & 52 & 31 & 1.88 & $1.16-3.03$ \\
\hline $30-50$ & 122 & 84 & 1.59 & $1.06-2.40$ \\
\hline$\geq 50$ & 28 & 32 & 1.00 & Ref. \\
\hline \multicolumn{5}{|l|}{ Sex } \\
\hline Male & 119 & 80 & 1.18 & $0.87-1.60$ \\
\hline Female & 83 & 67 & 1.00 & Ref. \\
\hline \multicolumn{5}{|l|}{ Education } \\
\hline Secondary and higher & 109 & 62 & 1.61 & $1.19-2.18$ \\
\hline Less than secondary & 93 & 85 & 1.00 & Ref. \\
\hline \multicolumn{5}{|l|}{ Occupation } \\
\hline Professional & 34 & 38 & 1.90 & $1.27-2.83$ \\
\hline Skilled & 69 & 52 & 1.53 & $1.01-2.33$ \\
\hline Nonskilled & 99 & 57 & 1.00 & Ref. \\
\hline \multicolumn{5}{|l|}{ Body mass index $\left(\mathrm{kg} / \mathrm{m}^{2}\right)$} \\
\hline$<25$ & 101 & 75 & 2.70 & $0.97-3.34$ \\
\hline $25-<30$ & 81 & 43 & 1.90 & $0.60-4.56$ \\
\hline$\geq 30$ & 20 & 29 & 1.00 & Ref. \\
\hline \multicolumn{5}{|c|}{ (ii) Lifestyle factors } \\
\hline \multicolumn{5}{|l|}{ Smoking } \\
\hline Never smoker & 69 & 61 & 1.48 & $1.03-2.13$ \\
\hline Ex-smoker & 61 & 41 & 1.31 & $0.90-1.90$ \\
\hline Smoker & 72 & 45 & 1.00 & Ref. \\
\hline \multicolumn{5}{|l|}{ Physical activity } \\
\hline Yes & 123 & 87 & 1.06 & $0.78-1.45$ \\
\hline No & 79 & 60 & 1.00 & Ref. \\
\hline \multicolumn{5}{|c|}{ (iii) History of back pain episode } \\
\hline \multicolumn{5}{|l|}{ Pain grade } \\
\hline Mild & 45 & 15 & 4.97 & $2.96-8.34$ \\
\hline Moderate & 125 & 79 & 2.59 & $1.79-3.75$ \\
\hline Severe & 32 & 53 & 1.00 & Ref. \\
\hline \multicolumn{5}{|l|}{ Pain site } \\
\hline Localized & 106 & 50 & 2.12 & $1.55-2.89$ \\
\hline Radiated & 96 & 97 & 1.00 & Ref. \\
\hline \multicolumn{5}{|l|}{ Pain Type } \\
\hline Recent & 60 & 18 & 5.39 & $3.38-8.57$ \\
\hline Periodic & 102 & 63 & 2.61 & $1.83-3.73$ \\
\hline Persistent & 40 & 66 & 1.00 & Ref. \\
\hline
\end{tabular}

${ }^{*}$ Result of univariate models.

$* * 95 \%$ confidence intervals.

For other studied prognostic factors, the results of the predictive model have found no significant association between them and the good back pain outcome. These results, however, appeared to be inconsistent with the reviewed back pain literature. Most of these factors, particularly the gender of patient, level of education $[11,15]$, and smoking [16-18], were found to be important risk factors for an increased incidence of LBP disability.

This study appeared to have a number of strengths that include the relatively large number of workers and exploration of the influence of different predictors at the same time. The study data were collected directly from the patients at the index consultation (no proxy respondents). Furthermore, combining the outcome variables as good and poor outcome (dichotomous variable) tends to minimize the number of the outcome variables and the patients are categorized in more homogeneous groups. Despite the exclusion of 51 subjects (12.7\%) from the study analysis because of nonattendance and/or nonresponse to phone call, the study power has not been affected as indicated by 
TABle 3: Prognostic factors of good back pain outcome based on predictor regression model, including variables being significant in Table 2.

\begin{tabular}{|c|c|c|c|c|}
\hline Variable & Good outcome (202 subjects) & Poor outcome (147 subjects) & $\mathrm{OR}^{*}$ & $95 \% \mathrm{CI}^{* *}$ \\
\hline \multicolumn{5}{|l|}{ Type of pain } \\
\hline Recent & 60 & 18 & 4.85 & $2.88-8.17$ \\
\hline Periodic & 102 & 63 & 1.91 & $1.15-4.22$ \\
\hline Persistent & 40 & 66 & 1.00 & Ref. \\
\hline \multicolumn{5}{|c|}{ Body mass index $\left(\mathrm{kg} / \mathrm{m}^{2}\right)$} \\
\hline$<25$ & 101 & 75 & 2.70 & $1.15-4.22$ \\
\hline $25-<30$ & 81 & 43 & 1.90 & $0.60-4.56$ \\
\hline$\geq 30$ & 20 & 29 & 1.00 & Ref. \\
\hline \multicolumn{5}{|l|}{ Occupation } \\
\hline Professional & 34 & 38 & 2.16 & $1.30-3.28$ \\
\hline Skilled & 69 & 52 & 1.28 & $0.79-2.07$ \\
\hline Nonskilled & 99 & 57 & 1.00 & Ref. \\
\hline \multicolumn{5}{|c|}{ Age group in years } \\
\hline$<30$ & 52 & 31 & 1.90 & $1.16-3.02$ \\
\hline $30-50$ & 122 & 84 & 1.70 & $1.05-3.01$ \\
\hline$\geq 50$ & 28 & 32 & 1.00 & Ref. \\
\hline \multicolumn{5}{|l|}{ Pain site } \\
\hline Localized & 106 & 50 & 1.50 & $1.01-2.01$ \\
\hline Radiated & 96 & 97 & 1.00 & Ref. \\
\hline
\end{tabular}

${ }^{*}$ Results of predictive regression model.

$* * 95 \%$ confidence intervals.

the observed narrowness of the confidence intervals obtained in almost all the estimated odds ratios.

This study has also number of limitations. Firstly, the population studied, despite being recruited from health insurance clinics that represent primary health care clinics, cannot be considered representative of the general population of low back pain patients. So, caution should be taken in generalizing the findings of this study.Although the study results can only be representative for similarly selected population (worker patients), the question of generalization to all Sharkia worker patients still proves uncertain as the studied subjects have only included worker patients consulted the health insurance clinics and there have been no available data estimating the total percent of workers attending these clinics in Sharkia governorate. Accordingly, future LBP outcome studies should address other sectors of population as well as other settings to clarify these findings and improve understanding of the prognostic factors influencing the low back pain outcome. Compliance to prescribed medications may affect the outcome of LBP; however, almost all patients in this study reported adherence to treatment on the second consultation. Finally, sick leave duration may also affect the outcome of LBP. Adjustment of all study analyses by sick leave duration, however, did not show any change in the observed associations.

In summary, the likelihood of improvement of low back pain is found to be affected by the characteristic levels of pain-related factors in terms of recency of pain, occupation of the patient, body mass index, and age of the patient at the index consultation.

\section{Acknowledgments}

The authors would like to thank all participating patients for their cooperation. They also thank all the physician and nursing staff in the studied clinics for their help and cooperation in collecting data of this study.

\section{References}

[1] R. A. Deyo and Y. J. Tsui-Wu, "Descriptive epidemiology of low-back pain and its related medical care in the United States," Spine, vol. 12, no. 3, pp. 264-268, 1987.

[2] G. B. J. Andersson, "Epidemiological features of chronic lowback pain,” Lancet, vol. 354, no. 9178, pp. 581-585, 1999.

[3] J. W. Frank, A. S. Brooker, S. E. DeMaio et al., "Disability resulting from occupational low back pain-part II: what do we know about secondary prevention? a review of the scientific evidence on prevention after disability begins," Spine, vol. 21, no. 24, pp. 2918-2929, 1996.

[4] B. Schiøttz-Christensen, G. L. Nielsen, V. K. Hansen, T. Schødt, H. T. Sørensen, and F. Olesen, "Long-term prognosis of acute low back pain in patients seen in general practice: a 1-year prospective follow-up study," Family Practice, vol. 16, no. 3, pp. 223-232, 1999.

[5] D. I. Rubin, "Epidemiology and risk factors for spine pain," Neurologic Clinics, vol. 25, no. 2, pp. 353-371, 2007.

[6] B. M. Wand, J. H. McAuley, L. Marston, and L. H. De Souza, "Predicting outcome in acute low back pain using different models of patient profiling," Spine, vol. 34, no. 18, pp. 19701975, 2009.

[7] J. Singer, J. R. Gilbert, T. Hutton, and D. W. Taylor, "Predicting outcome in acute low-back pain," Canadian Family Physician, vol. 33, pp. 655-659, 1987. 
[8] M. J. Ravenek, M. M. Bryson-Campbell, L. Shaw, and I. D. Hughes, "Perspectives on prevention, assessment, and rehabilitation of low back pain in WORK," Work, vol. 35, no. 3, pp. 269-282, 2010.

[9] L. Hestbaek, C. Leboeuf-Yde, and K. O. Kyvik, "Are lifestylefactors in adolescence predictors for adult low back pain? A cross-sectional and prospective study of young twins," BMC Musculoskeletal Disorders, vol. 7, article 27, 2006.

[10] SAS Institute Inc. Proprietary Software Release 8.2., SAS Institute Inc, Cary, NC, USA, 1999.

[11] M. Von Korff, R. A. Deyo, D. Cherkin, and W. Barlow, "Back pain in primary care: outcomes at 1 year," Spine, vol. 18, no. 7 , pp. 855-862, 1993.

[12] J. A. Hayden, R. Chou, S. Hogg-Johnson, and C. Bombardier, "Systematic reviews of low back pain prognosis had variable methods and results-guidance for future prognosis reviews," Journal of Clinical Epidemiology, vol. 62, no. 8, pp. 781-796.e1, 2009.

[13] B. Natvig, W. Eriksen, and D. Bruusgaard, "Low back pain as a predictor of long-term work disability," Scandinavian Journal of Public Health, vol. 30, no. 4, pp. 288-292, 2002.

[14] E. F. Harkness, G. J. Macfarlane, E. S. Nahit, A. J. Silman, and J. McBeth, "Risk factors for new-onset low back pain amongst cohorts of newly employed workers," Rheumatology, vol. 42, no. 8, pp. 959-968, 2003.

[15] G. J. Macfarlane, E. Thomas, P. R. Croft, A. C. Papageorgiou, M. I. V. Jayson, and A. J. Silman, "Predictors of early improvement in low back pain amongst consulters to general practice: the influence of pre-morbid and episode-related factors," Pain, vol. 80, no. 1-2, pp. 113-119, 1999.

[16] K. B. Hagen, H. H. Holte, K. Tambs, and T. Bjerkedal, "Socioeconomic factors and disability retirement from back pain. A 1983-1993 population-based prospective study in Norway," Spine, vol. 25, no. 19, pp. 2480-2487, 2000.

[17] W. Eriksen, B. Natvig, and D. Bruusgaard, "Smoking, heavy physical work and low back pain: a four-year prospective study," Occupational Medicine, vol. 49, no. 3, pp. 155-160, 1999.

[18] T. Otani, M. Iwasaki, A. Ohta et al., "Low back pain and smoking in a community sample in Japan," Journal of Occupational Health, vol. 44, no. 4, pp. 207-213, 2002. 


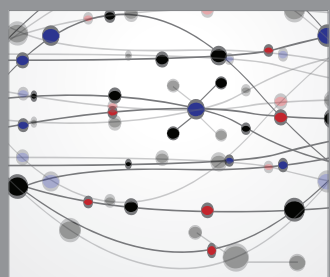

The Scientific World Journal
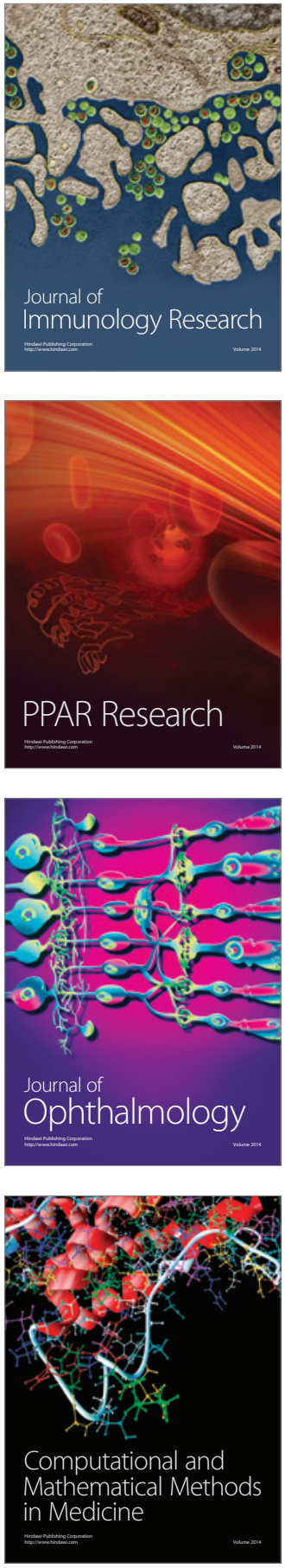

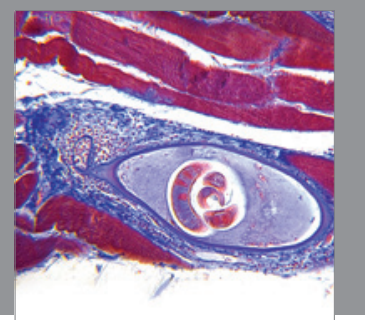

Gastroenterology

Research and Practice
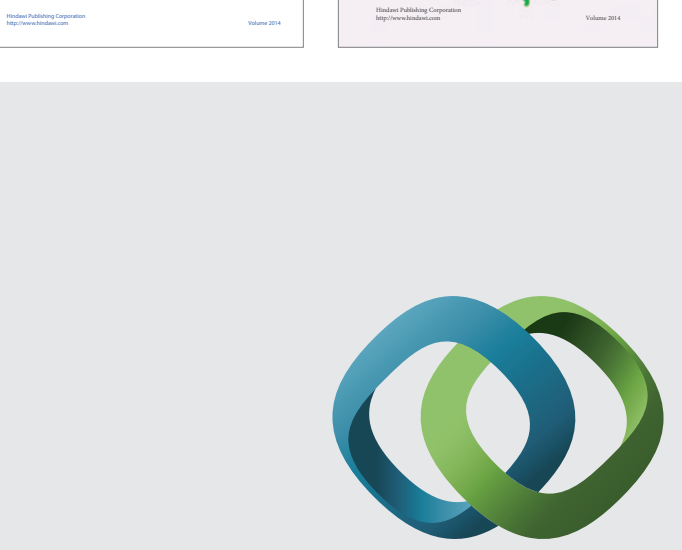

\section{Hindawi}

Submit your manuscripts at

http://www.hindawi.com
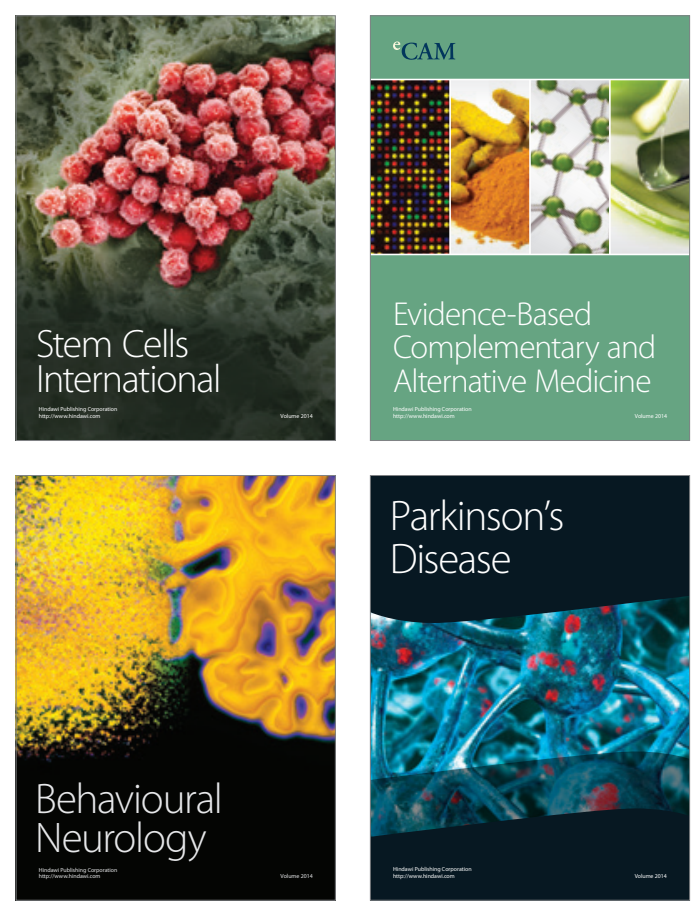

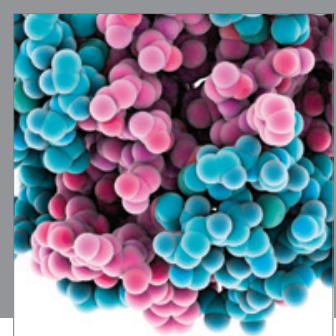

Journal of
Diabetes Research

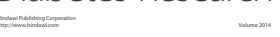

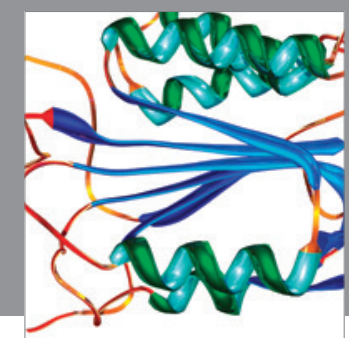

Disease Markers
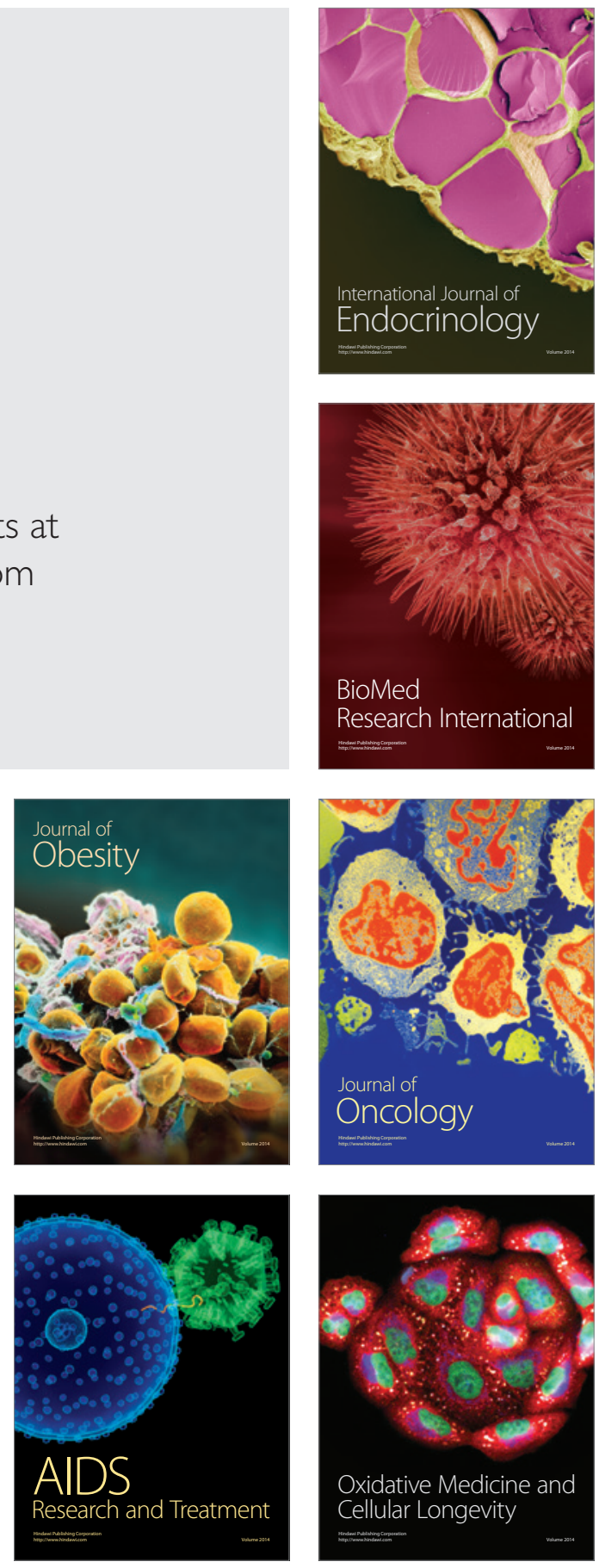